\title{
Childhood Maternal School Leaving Age (Level of Education) and Risk Markers of Metabolic Syndrome in Mid-Adulthood: Results from the 1958 British Birth Cohort
}

This article was published in the following Dove Press journal:

Diabetes, Metabolic Syndrome and Obesity: Targets and Therapy

\section{Chukwuma Iwundu \\ Dong Pang \\ Yannis Pappas (D)}

Institute for Health Research, University of Bedfordshire, Luton, UK
Correspondence: Chukwuma Iwundu Institute for Health Research, University of Bedfordshire, Luton, Bedfordshire LU2 8LE, UK

Tel +441582743797

Fax +44 I5827439|8

Email Chukwuma.iwundu@study.beds.ac. uk
Purpose: The aim of this study is to investigate the relationship between childhood maternal level of education (CMLE) and changes in anthropometric and laboratory risk markers of metabolic syndrome (MetS) in mid-adulthood using results from the 1958 British Birth Cohort Study.

Design: Cohort study.

Participants: A total of 9376 study samples consisting of subjects that participated in the biomedical survey of the national child development study (NCDS) carried out between 2002 and 2004 were used for the analysis.

Main Outcome Measures: Five risk markers of MetS: (i) HDL-cholesterol (ii) triglyceride (iii) blood pressure (BP) including systolic (SBP) and diastolic (DBP) (iv) waist circumference (WC) and (v) glycated haemoglobin (HbA1c).

Methods: The NCDS or the 1958 British birth cohort data deposited in the UK data service by the centre for longitudinal studies were used for analyses. Ordinary least squares regression was used to determine unit changes in the outcome variables given CMLE.

Results: The estimates for unadjusted regression analysis of individual risk markers indicated a significant relationship between CMLE and alterations in the five risk markers of MetS (HDL-cholesterol, triglyceride, WC, HbA1c, and BP) in midlife. After adjustment for birth and lifestyle characteristics/health behaviours, the relationship between CMLE and the risk markers was attenuated for HDL-cholesterol, triglycerides, and $\mathrm{HbAlc}$ but remained significant for WC 0.70 (95\% confidence interval (CI) $0.065-1.30, \mathrm{p}<0.001)$ and SBP 1.48 (95\% CI 0.48-2.47 p<0.001).

Conclusion: There was a positive association between lower CMLE and the risk of MetS using the NCDS data. Lifestyle characteristics may be influential determinants of MetS risk in mid-adulthood.

Keywords: maternal education, metabolic syndrome, risk markers, biomedical survey, NCDS data

\section{Introduction}

Metabolic syndrome (MetS) is generally defined as a clustering of cardiometabolic abnormalities including central obesity, hypertension, dyslipidaemia, hyperglycaemia, and insulin resistance with central obesity. ${ }^{1}$ These metabolic disorders are significant risk factors for MetS and cardiovascular disease (CVD) generally regarded as the primary clinical outcome. ${ }^{2}$ The risk factors of MetS, as defined 
by the National Cholesterol Education Program (NCEP) Adult Treatment Panel III (ATP III) criteria, ${ }^{3}$ are recurrent features in the aetiology of many non-communicable diseases. ${ }^{4}$ Their importance in the health and wellbeing of an individual or group cannot be overemphasised as changes in these risk factors are responsible for a greater percentage of all death globally and are expected to cause about $80 \%$ of all deaths in $2020 .^{4,5}$ The risk factors for MetS often develop in early childhood and are maintained over a life-course. The multifactorial origin of MetS will be well understood if the risk factors are analysed individually in relation to socioeconomic status (SES). ${ }^{6}$ SES and behavioural factors such as alcohol consumption, exercise frequency and smoking status can lead to changes in these risk factors resulting to chronic disease conditions. ${ }^{7-10}$ Parental level of education as an indicator of SES has been found to be an important marker for characteristics that are related to increased risk of MetS, such as limited access to health facilities and treatment, physical stress, and lack of motivation to engage in activities that are beneficial to health. ${ }^{6}$

The aim of this study is to investigate the relationship between CMLE and anthropometric and laboratory risk markers of MetS including WC, BP, triglycerides, HDLcholesterol and glycated haemoglobin (HbA1c). The result is expected to show the impact of CMLE on MetS risk markers in midlife. Knowledge and understanding of the magnitude of change of these risk markers in relation to CMLE will help healthcare professionals to design an early intervention strategies on cardiometabolic health risk.

\section{Method}

This study was carried out using data obtained from a cohort of individuals born in a certain week in March 1958 who were invited to participate in a biomedical survey in 2002 (age 44). This cohort of individuals is known as the 1958 British Birth Cohort or the National Child Development Study (NCDS). An ongoing socioeconomic and health survey are being carried out on this cohort by the University of London centre for longitudinal studies. The 2002 biomedical survey, which included 9376 participants, was designed to obtain risk factors and measures which determine ill-health, with the aim of establishing, through exploration, the influence of child development, environment, and lifestyle on ill health. In addition, the survey was intended to help researchers address a wide range of issues relating to cardiovascular health, anthropometry, visual and hearing impairment, allergic and respiratory disease, and mental health. Furthermore, the survey will help researchers to understand the psychological and physiological functions among adults in their midlife.

\section{Maternal Level of Education}

In England and Wales, the Law states a minimum age for a child to stay in full-time education. The Education Act of 1996 made it an obligation for parents to have their children in full-time education from the age 5 to $16,{ }^{11}$ although the attendance of school is not compulsory, as section 2 of the act allows for home schooling. The minimum compulsory school leaving age of 16 came into force in $1972 .{ }^{12}$ This was preceded by the Butler Education Act of 1944 which came into force in 1947 and the Fisher Education Act of 1918 which was enforced in $1921 .^{13,14}$ The 1944 Act raised the minimum school leaving age from 14 to 15 years ${ }^{15}$ and the 1918 Act made it compulsory for children to be in full-time education from age 5 to 14 years. ${ }^{13}$

In this study, CMLE was derived from the provisions of the 1918 and 1944 Education Act. The two Education Acts were enforced prior to 1958 when the first NCDS survey was carried out, implying that the parents of the cohort members left compulsory education at age 14 or 15 . The CMLE variable was dichotomised to "leaving full time education at or before minimum school leaving age" and "staying in full time education after minimum school leaving age". The cohort members whose mothers left school on or before minimum school leaving age were categorised as low CMLE and the participants whose mothers were in compulsory education after the minimum school leaving age were categorised as high CMLE.

\section{Outcome Variables}

In the 2001 NCEP ATP III definition, ${ }^{3}$ an individual is said to have MetS if he/she presents at least 3 of the 5 risk factors: (1) abdominal obesity and WC greater than $102 \mathrm{~cm}$ for men and $88 \mathrm{~cm}$ for women, (2) low HDL cholesterol $(<40 \mathrm{mg} / \mathrm{dL}$ or $1.04 \mathrm{mmol} / \mathrm{L}$ for men and $<50 \mathrm{mg} / \mathrm{dL}$ or $1.3 \mathrm{mmol} / \mathrm{L}$ for women), (3) elevated triglyceride $(\geq 150 \mathrm{mg} / \mathrm{dL}$ or $1.7 \mathrm{mmol} / \mathrm{L})$, (4) elevated BP (>130 $\mathrm{mmHg}$ for SBP and $>85 \mathrm{mmHg}$ for DBP), and (5) elevated fasting glucose (FG) $(\geq 110 \mathrm{mg} / \mathrm{dL}$ ). In this study, glycated haemoglobin ( $\mathrm{HbAlc}$ ) was used in place of $\mathrm{FG}$ as the hyperglycaemic component in the diagnosis of MetS. Due to the nature of the survey and the considerably large 
sample size, it would have been challenging and very complex to obtain an accurate FG from this group of participants. The ATP III criteria did not require evidence of insulin resistance for diagnosis of MetS. Like the WHO criteria, ATP III allowed for diagnosis of MetS if type 2 diabetes is present because of the high risk of CVD among patients with type 2 diabetes.

WC was measured using body tension tape. Everyone was eligible for the measurement except those who did not consent, and pregnant women. The equipment used for measurement of blood pressure was an OMRON 97 blood pressure monitor with standard and large cuffs for adults. The measurements were taken by trained nurses, and pregnant women were excluded. Three outcome measures HbAlc, HDL-Cholesterol and triglyceride were derived from blood samples. A non-fasting venous blood sample was collected by nurses in four separate Sarstedt polypropylene tubes containing (i) EDTA anticoagulant, sent to St George's Hospital for processing, (ii) citrate anticoagulant, sent to Royal Victoria Infirmary, Newcastle for processing, (iii) no anticoagulant, sent to Royal Victoria Infirmary, Newcastle for processing, and (iv) CPDA anticoagulant, sent to ALPAC Laboratory, Bristol for processing. The tube that contained no anticoagulant was used to analyse triglycerides and HDLCholesterol with serum supernatant obtained after centrifuging the blood sample. The measurement for triglyceride and HDL-Cholesterol was done using an Olympus model AU 640 auto-analyser. $0.5 \mathrm{~mL}$ of blood in the tube that contained citrate was analysed for glycated haemoglobin (HbAlc). The blood sample was measured for HbA1c by ion exchange high chromatography using the Tosoh Alc 2.2 Glycohaemoglobin Analyser HLC-723GHB. In this study, the value of $\mathrm{HbAlc}$ is expressed as a percentage Diabetes Control and Complication Trial unit. ${ }^{16}$

\section{Confounding Variables}

The first step in data analysis was to identify and select the variables that would be included in the model used to address the research questions. The aim of this study was used to determine the choice of the outcome variables and independent variables of interest. The candidate variables were manually identified based on the knowledge and information obtained from prior studies. ${ }^{8,17-22}$

To effectively estimate the association between CMLE and MetS in midlife, confounding factors were included in the analysis. The confounders were placed in 2 groups. The first group consisted of characteristics that were observed in childhood. These were gender (male, female), maternal age at birth (years), birth weight (kilograms), breastfeeding (no, under one month, over one month) and father's social class (non-manual, manual). The second group of confounding factors were lifestyle characteristics and health behaviours in adulthood. These were smoking at age 42 (current smoker, ex-smoker, never smoked), alcohol frequency (infrequent/never, daily, weekly, monthly), exercise frequency (regular, some days, little or less often), fruit consumption (daily some days, occasionally, never), sweet consumption (daily, some days, occasionally, never), and BMI (moderate/not obese, highly obese).

\section{Handling of Missing Data}

Multiple imputation by chained equations was used to handle missing data in the independent and outcome variables. The number of imputations used was 10 , meaning 10 imputed data sets were created. The imputed datasets were examined to see if the imputation appeared reasonable by checking if the standard deviations of the imputed datasets appeared similar. Before the primary analysis, the fit of the imputation model was checked to compare the imputed values with observed values to check for implausible imputed values prior to analysis. For categorical variables, graphs and tables of proportion of frequencies were used. Due to issue with data distribution, the variable that indicates triglyceride was log transformed prior to analysis.

\section{Statistical Analysis}

Descriptive statistics were generated to get sense of the data and to help to summarise and understand the characteristics of the study population and relationships between variables. The descriptive statistics were used to compare the frequency and relative frequency of the categorical variables in relation to CMLE for both male and female participants. They were used to compare the mean of the outcome variables in relation to CMLE for both male and female participants. An exploratory two-sample $t$-test was used to help give insight on the outcome variables. A two-sample $t$-test between high and low CMLE was computed for each of the 5 risk markers of MetS, to test the null hypothesis that there was no difference in risk markers of MetS between high and low CMLE groups. Participants grouped in relation to their CMLE were compared based on the average level of markers of MetS. Before comparing the groups using t-tests, the data was 
checked to ensure it met the assumptions of the $t$-test. This was done using box plots, normal quantile plots and tests to indicate whether variance in the outcome variable was significant among the groups (high and low CMLE).

The associations between CMLE and each of the five risk markers of MetS were estimated using ordinary least squares regression (OLR) linear regression. Four models were fitted for each risk marker. In model 1, the crude, or unadjusted, associations between CMLE and each of the five risk markers were estimated. In model 2 , the confounding effect of characteristics at birth was explored. Model 3 involved examining the influence of lifestyle characteristics and health behaviours on the associations between CMLE and each of the MetS risk markers. In model 4, the overall effects of birth and lifestyle characteristics and health behaviours were explored. The results obtained for transformed outcome variable (triglyceride) were recorded as percentage difference.

\section{Results}

Table 1 shows the characteristics of study participants at baseline. Apart from missing values and non-response, the data used for the analysis contained 4330 male and 4363 female participants. Of these numbers, $27 \%$ of males were classed as high CMLE and $73 \%$ as low CMLE. Similar proportion as male for high and low CMLE was observed for female participants.as. The mean level of HDLcholesterol, WC, SBP, DBP, and HbA1c tended to be higher in participants with low CMLE than those with high CMLE. About $80 \%$ of male and $90 \%$ of female participants classed as low CMLE were born to parents that belong to the manual occupation social class. For high CMLE only $43 \%$ of male and $45 \%$ of female participants were born to parents in manual occupations. The proportion of participants that smoked was higher for low CMLE compared to high CMLE. Similarly, participants classed as low CMLE were shown to be more obese than those with high CMLE.

Table 2 presents the results of two-sample t-tests. The results show that the average HDL-cholesterol for male participants with high CMLE was $1.46 \mathrm{mmol} / \mathrm{L}$, compared to $1.43 \mathrm{mmol} / \mathrm{L}$ for those that had low CMLE. The difference in mean was $0.03 \mathrm{mmol} / \mathrm{L}$, which is significantly different from zero with a two-tailed $\mathrm{p}$ value of 0.001 . This implied that male participants with high CMLE were in significantly better health than those with low CMLE. A similar result was recorded for female participants. The mean difference in waist circumference for female participants between high and low CMLE groups was is -2.60 $\mathrm{mmol} / \mathrm{L}$. The two-tailed $\mathrm{p}$ value was 0.001 , indicating that there was a difference in WC between high and low CMLE for female participants. This showed that female participants classed as low CMLE were more likely to have a larger WC than those classed as high CMLE.

In Table 3, the crude (unadjusted) regression analysis showed a significant relationship between CMLE and all risk markers of MetS in model 1. These relationships did not change in model 2. This means that the inclusion of the childhood confounding factors of gender, maternal age at birth, birth weight, breastfeeding, and father's social class did not impact on the relationship between CMLE and the risk markers of MetS. In model 3, there was a significant relationship between CMLE and all risk markers of MetS except HbA1c after adjustment for the confounding lifestyle characteristics/health behaviours of smoking at age 42, alcohol frequency, exercise frequency, fruit consumption, sweet consumption, and BMI. A coefficient of -0.04 $(95 \% \mathrm{CI},-0.06,-0.01, \mathrm{p}<0.001)$ indicated that HDLcholesterol decreased by $0.04 \mathrm{mmol} / \mathrm{L}$ in participants with low CMLE compared to those with high CMLE. Similarly, low CMLE resulted in increased WC of $1.20 \mathrm{~cm}(95 \%$ CI $1.27,2.54, \mathrm{p}<0.001)$ compared to high CMLE. After adjustment for birth and lifestyle characteristics/health behaviours, the relationships between CMLE and the risk markers were significant for waist circumference and blood pressure but not for triglyceride, HDLcholesterol, and HbAlc. On average, participants in the low CMLE group had $0.70 \mathrm{~cm}(95 \%$ CI $0.065,1.30$, $\mathrm{p}<0.001)$ increased WC compared to those with high CMLE, if birth and lifestyle characteristics and other factors indicating health behaviours were kept constant. An increased level of SBP of $1.48 \mathrm{mmHg}$ (95\% CI 0.48, 2.47 $\mathrm{p}<0.001)$ was recorded in participants with low CMLE compared to those with high CMLE.

\section{Discussion}

In this study, we have analysed the association between CMLE as a measure of SES and risk markers of MetS. The results of the regression analysis for the crude estimates indicated a significant association between CMLE and the five risk markers for MetS. The association stays the same after adjustment for characteristics at birth. The overall adjustment for birth characteristics and lifestyle factors showed that WC and blood pressure (systolic and diastolic) were significantly related to CMLE. Although several published studies have looked at the relationship between socioeconomic indicators of MetS in adulthood, to our 
Table I Baseline Characteristics of Participants

\begin{tabular}{|c|c|c|c|c|c|c|}
\hline \multicolumn{7}{|c|}{ Childhood Maternal Level of Education } \\
\hline \multirow[t]{2}{*}{ Variables } & \multicolumn{3}{|l|}{ Male } & \multicolumn{3}{|l|}{ Female } \\
\hline & High & Low & Total & High & Low & Total \\
\hline \multicolumn{7}{|l|}{ Maternal age } \\
\hline$\leq 19$ & $29(2.4)$ & $172(5.3)$ & $20 \mathrm{I}(4.6)$ & $44(3.7)$ & $202(6.2)$ & $246(5.5)$ \\
\hline $20-24$ & $308(26)$ & $938(29.1)$ & $1246(28.3)$ & $294(24.4)$ & $959(29.6)$ & $1253(28.2)$ \\
\hline $25-29$ & $438(37)$ & $1075(33.3)$ & $1513(34.3)$ & $457(38)$ & $1014(31.3)$ & $147 \mid(33.1)$ \\
\hline $30-34$ & $263(22.2)$ & $607(18.8)$ & $870(19.7)$ & $267(22.2)$ & $667(20.6)$ & $934(21)$ \\
\hline$\geq 35$ & $146(12.3)$ & $432(13.4)$ & $578(13.1)$ & $142(\mid 1.8)$ & $40 I(12.4)$ & $543(12.2)$ \\
\hline Total & $1184(100)$ & $3224(100)$ & $4408(100)$ & $1204(100)$ & $3243(100)$ & $4447(100)$ \\
\hline \multicolumn{7}{|l|}{ Breast Feeding } \\
\hline No & $245(23.4)$ & $942(32.8)$ & II $87(30.3)$ & $246(22.7)$ & $926(31.8)$ & $1172(29.4)$ \\
\hline Under one month & $205(19.5)$ & $718(25)$ & $923(23.5)$ & $223(20.6)$ & $755(26)$ & $978(24.5)$ \\
\hline Over one month & $599(57.1)$ & $121 \mid(42.2)$ & $1810(46.2)$ & $615(56.7)$ & $1227(42.2)$ & $1842(46.1)$ \\
\hline Total & $1049(100)$ & $287 \mid(100)$ & $3920(100)$ & $1084(100)$ & $2908(100)$ & $3992(100)$ \\
\hline \multicolumn{7}{|l|}{ Social Class at Birth } \\
\hline Non manual & $655(57.2)$ & $612(19.9)$ & $1267(30)$ & $632(54.7)$ & $593(19.2)$ & $1225(28.9)$ \\
\hline Manual & $490(42.8)$ & $246 \mid(80.1)$ & $2951(70)$ & $523(45.3)$ & $2496(80.8)$ & 3019 (7I.I) \\
\hline Total & $1145(100)$ & $3073(100)$ & $4218(100)$ & $1155(100)$ & $3089(100)$ & $4244(100)$ \\
\hline \multicolumn{7}{|l|}{ Smoking at age 42} \\
\hline Current smoker & $217(19)$ & $793(25.6)$ & $1010(23.8)$ & $220(18.8)$ & $838(26.6)$ & $1058(24.5)$ \\
\hline Ex/occ-smoker & $389(34)$ & $937(30.2)$ & $1326(3 \mid .2)$ & $37 \mid(31.7)$ & $888(28.1)$ & $1259(29.1)$ \\
\hline Never smoked & $539(47.1)$ & I 372 (44.2) & $1911(45)$ & $579(49.5)$ & $1430(45.3)$ & $2009(46.4)$ \\
\hline Total & $1145(100)$ & $3102(100)$ & $4247(100)$ & $1170(100)$ & $3156(100)$ & $4326(100)$ \\
\hline \multicolumn{7}{|l|}{ Alcohol Frequency } \\
\hline Infrequently/never & 138 (II.7) & $489(15.3)$ & $627(14.4)$ & $249(20.8)$ & $955(29.6)$ & $1204(27.2)$ \\
\hline Daily & $428(36.4)$ & $962(30.1)$ & $1390(31.8)$ & $337(28.1)$ & $58 \mid(\mid 8)$ & $918(20.7)$ \\
\hline Monthly & $22 I(18.8)$ & $674(2 I . I)$ & $895(20.5)$ & $238(19.8)$ & $763(23.6)$ & $100 \mid(22.6)$ \\
\hline Weekly & $389(33.1)$ & $1068(33.4)$ & $1457(33.3)$ & $375(31.3)$ & $928(28.8)$ & $1303(29.4)$ \\
\hline Total & $1176(100)$ & $3193(100)$ & $4369(100)$ & $1199(100)$ & $3227(100)$ & $4426(100)$ \\
\hline \multicolumn{7}{|l|}{ Exercise Frequency } \\
\hline All the time & $248(26.9)$ & $787(33.8)$ & $1035(31.8)$ & $35 \mathrm{I}(38.4)$ & $834(36.8)$ & $1185(37.3)$ \\
\hline Some days & $548(13.7)$ & $1242(53.4)$ & $1790(55.1)$ & $468(5 I .3)$ & $1193(52.6)$ & $|66|(52.2)$ \\
\hline Little or less often & $126(13.7)$ & $299(12.8)$ & $425(13.1)$ & $94(10.3)$ & $24 I(10.6)$ & $335(10.5)$ \\
\hline Total & $922(100)$ & $2328(100)$ & $3250(100)$ & $913(100)$ & $2268(100)$ & $3181(100)$ \\
\hline \multicolumn{7}{|l|}{ Fruit } \\
\hline All the time & $538(46.9)$ & $1352(43.6)$ & $1890(44.5)$ & $792(67.7)$ & I833 (58.1) & $2625(60.7)$ \\
\hline Some days & $413(36)$ & $944(30.4)$ & 1357 (31.9) & $262(22.4)$ & $807(25.6)$ & $1069(24.7)$ \\
\hline Occasionally & $176(I 5.4)$ & $702(22.6)$ & $878(20.7)$ & $101(8.6)$ & $450(\mid 14.3)$ & $551(12.7)$ \\
\hline Never & $19(1.7)$ & $104(3.4)$ & $123(2.9)$ & $15(1.3)$ & $66(2.1)$ & $81(1.9)$ \\
\hline Total & $1146(100)$ & $3102(100)$ & $4248(100)$ & $1170(100)$ & $3156(100)$ & $4326(100)$ \\
\hline \multicolumn{7}{|l|}{ Sweet } \\
\hline All the time & $194(16.9)$ & $614(19.8)$ & $8089(19)$ & $229(19.6)$ & $695(22)$ & $924(21.4)$ \\
\hline Some days & $526(45.9)$ & $1249(40.3)$ & $1775(4 \mid .8)$ & $486(4 I .5)$ & $1219(38.6)$ & 1705 (39.4) \\
\hline Occasionally & $37 \mid(32.4)$ & $1057(34.1)$ & $1428(33.6)$ & $416(35.6)$ & $1105(35)$ & $|52|$ (35.2) \\
\hline Never & $55(4.8)$ & $182(5.9)$ & $237(5.6)$ & $39(3.3)$ & $137(4.3)$ & $176(4.1)$ \\
\hline Total & $1146(100)$ & $3102(100)$ & $4248(100)$ & $1170(100)$ & $3156(100)$ & $4326(100)$ \\
\hline
\end{tabular}

(Continued) 
Table I (Continued).

\begin{tabular}{|c|c|c|c|c|c|c|}
\hline \multicolumn{7}{|c|}{ Childhood Maternal Level of Education } \\
\hline \multirow[t]{2}{*}{ Variables } & \multicolumn{3}{|l|}{ Male } & \multicolumn{3}{|l|}{ Female } \\
\hline & High & Low & Total & High & Low & Total \\
\hline \multicolumn{7}{|l|}{ BMI } \\
\hline Moderate/not obese & II 29 (97.1) & $2950(93.1)$ & $4079(94.2)$ & II 07 (93.7) & $2862(90)$ & $3969(91)$ \\
\hline Highly obese & $34(0.9)$ & $217(6.9)$ & $251(5.8)$ & $75(6.3)$ & $319(10)$ & $394(9)$ \\
\hline Total & $1163(100)$ & $3167(100)$ & $4330(100)$ & $1182(100)$ & $3181(100)$ & $4363(100)$ \\
\hline Birth weight & $3.5( \pm 0.5 \mathrm{I})$ & $3.4( \pm 0.5)$ & $3.4( \pm 0.5)$ & $3.3( \pm 0.5)$ & $3.2( \pm 0.5)$ & $3.25( \pm 0.5)$ \\
\hline HDL Cholesterol & $1.46( \pm 0.34)$ & $1.43( \pm 0.33)$ & $1.43( \pm 0.34)$ & $1.8( \pm 0.4 \mathrm{I})$ & $\mathrm{I} .70( \pm 0.4 \mathrm{I})$ & $\mathrm{I} .70( \pm 0.4 \mathrm{I})$ \\
\hline Triglyceride & $2.4 I( \pm I .8 I)$ & $2.53( \pm 1.8)$ & $2.50( \pm 1.8)$ & $1.45( \pm I)$ & $1.65( \pm 1.18)$ & $1.6( \pm 1.13)$ \\
\hline Waist circumference & $97.03( \pm 10.3)$ & $99( \pm 11.5)$ & $98.5( \pm I 1.23)$ & $83.8( \pm 12.3)$ & $86.4( \pm 13.04)$ & $85.5( \pm 13)$ \\
\hline Systolic BP & $13 \mid( \pm|5|)$. & $133( \pm 15.6)$ & $132( \pm 15.4)$ & $119( \pm 15.1)$ & $121( \pm 16)$ & $120( \pm 16)$ \\
\hline Diastolic BP & $81( \pm I I)$ & $82( \pm I I)$ & $82( \pm I I)$ & $75( \pm 10.4)$ & $76( \pm I I)$ & $75.5( \pm)$ \\
\hline Hbalc & $5.26( \pm 0.6)$ & $5.33(0.8)$ & $5.3( \pm 0.8)$ & $5.1( \pm 0.6)$ & $5.2( \pm 0.7)$ & $5.2( \pm 0.6)$ \\
\hline $\mathrm{N}$ & 1163 (26.9) & $3167(73.1)$ & $4330(100)$ & $1182(27.1)$ & $3181(72.9)$ & $4363(100)$ \\
\hline
\end{tabular}

Notes: Data are \pm standard deviation (sd) or absolute numbers $(\%), \mathrm{n}=$ the number of sample and the proportion or percentage of the sample is in bracket, $\mathrm{N}=$ total number of sample for male or female participants grouped according to the level of education. High indicates participants whose mothers stayed in school after minimum school living age. Low indicates leaving school on or before minimum school leaving age. HDL-cholesterol, Triglyceride, Waist Circumference, Systolic BP, Diastolic BP, and $\mathrm{HbAlc}$ are the outcome variables. Maternal age, breast feeding, birth weight and fathers social class indicates participants characteristics during birth. Smoking at age 42 , alcohol frequency, exercise frequency fruit consumption, sweet consumption and BMI represents participants lifestyle characteristics and health behaviours.

Table 2 Comparison of Childhood Maternal Level of Education in Relation to Risk Markers of Metabolic Syndrome

\begin{tabular}{|c|c|c|c|c|c|c|c|c|c|}
\hline \multirow[t]{3}{*}{ Outcome Variables } & \multicolumn{6}{|c|}{ Childhood Maternal Level of Education } & \multirow[t]{3}{*}{ Mean Diff } & \multirow[t]{3}{*}{$P$ value } & \multirow[t]{3}{*}{ 95\% Conf. Interval } \\
\hline & \multicolumn{3}{|l|}{ High } & \multicolumn{3}{|l|}{ Low } & & & \\
\hline & $\mathbf{n}$ & Mean (sd) & SE & $\mathbf{n}$ & Mean (sd) & SE & & & \\
\hline \multicolumn{10}{|l|}{ Male } \\
\hline HDL Cholesterol & 1006 & $1.46( \pm 0.34)$ & 0.01 & 2699 & $1.43( \pm 0.33)$ & 0.01 & 0.03 & 0.001 & $0.01,0.06$ \\
\hline Triglyceride & 1004 & $0.69( \pm 0.60)$ & 0.02 & 2700 & $0.75( \pm 0.57)$ & 0.01 & -0.06 & 0.002 & $-0.10,-0.017$ \\
\hline Waist circumference & 1176 & $97.03( \pm 10.3)$ & 0.30 & 3198 & $99( \pm 11.5)$ & 0.17 & -2.00 & 0.001 & $-2.71,-1.22$ \\
\hline Systolic BP & 1177 & $13 \mid( \pm \mid 5.1)$ & 0.44 & 3195 & $133( \pm \mid 5.6)$ & 0.28 & -2.00 & 0.001 & $-3.00,-1.00$ \\
\hline Diastolic BP & 1177 & $81( \pm I I)$ & 0.31 & 3195 & $82( \pm I I)$ & 0.20 & -1.00 & 0.001 & $-2.10,-0.66$ \\
\hline $\mathrm{HbAlc}$ & 1022 & $5.26( \pm 0.6)$ & 0.02 & 2745 & $5.33(0.8)$ & 0.02 & -0.07 & 0.01 & $-0.12,-0.02$ \\
\hline \multicolumn{10}{|l|}{ Female } \\
\hline HDL Cholesterol & 982 & $1.8( \pm 0.41)$ & 0.01 & 2691 & $1.70( \pm 0.4 I)$ & 0.01 & 0.10 & 0.001 & $0.08,0.14$ \\
\hline Triglyceride & 980 & $0.22( \pm 0.5 \mathrm{I})$ & 0.02 & 2688 & $0.34( \pm 0.54)$ & 0.01 & -0.12 & 0.001 & $-0.15,-0.08$ \\
\hline Waist circumference & 1,192 & $83.8( \pm \mid 2.3)$ & 0.36 & 3214 & $86.4( \pm 13.04)$ & 0.23 & -2.60 & 0.001 & $-3.46,-1.76$ \\
\hline Systolic BP & $\mathrm{I}, 184$ & $119( \pm 15.1)$ & 0.44 & 3197 & $121( \pm 16)$ & 0.28 & -2.00 & 0.001 & $-3.04,-1.00$ \\
\hline Diastolic BP & 1,183 & $75( \pm 10.4)$ & 0.30 & 3197 & $76( \pm I I)$ & 0.20 & -1.00 & 0.02 & $-|.5|,-0.08$ \\
\hline $\mathrm{HbAlc}$ & 1,006 & $5.1( \pm 0.6)$ & 0.02 & 2720 & $5.2( \pm 0.7)$ & 0.01 & -0.1 & 0.01 & $-0.12,-0.02$ \\
\hline
\end{tabular}

Notes: Data are \pm standard deviation (sd), $\mathrm{n}=$ the number of samples, SE is the standard error, mean diff is the difference between the mean of high- and low-level maternal education. High indicates participants whose mothers stayed in school after minimum school living age, Low indicates leaving school on or before minimum school leaving age. HDL-cholesterol, Triglyceride (log transformed), Waist Circumference, Systolic BP, Diastolic BP, and HbAIc are the outcome variables.

knowledge this is the first study that collectively looked at the unadjusted and adjusted effects of CMLE and the level of risk markers of MetS using NCDS data. In this study, we emphasised the crude estimates and estimates resulting from adjustment due to birth characteristics and lifestyle and health behaviours in midlife.

\section{CMLE and Lipid Profile}

An individual's lipid profile is mainly defined by the cholesterol and triglyceride level. In this study, CMLE was found to be related with changes in the level of HDL-cholesterol and triglycerides in midlife. The results of the unadjusted regression analysis and those that 
Table 3 Association Between Childhood Maternal Level of Education and Metabolic Syndrome in Mid-Adulthood

\begin{tabular}{|c|c|c|c|c|c|c|}
\hline & \multicolumn{6}{|l|}{ Outcome Variables } \\
\hline & HDL Cholesterol & Waist Circumference & HbAlc & Triglyceride & Systolic BP & Diastolic BP \\
\hline \multicolumn{7}{|l|}{ Model I } \\
\hline \multicolumn{7}{|l|}{ Education } \\
\hline \multicolumn{7}{|c|}{ High level(ref) } \\
\hline Low level & $-0.07 * * *(-0.08,-0.04)$ & $2.32 * * * *(1.67,3.00)$ & $0.07 * * *(0.04,0.11)$ & $0.16 * * *(0.08,0.24)$ & $2.00 * * *(1.19,2.78)$ & $1.10 * * *(0.57-1.61)$ \\
\hline \multicolumn{7}{|c|}{ Model 2 Adjusted for characteristics at birth } \\
\hline \multicolumn{7}{|l|}{ Education } \\
\hline \multicolumn{7}{|c|}{ High level(ref) } \\
\hline Low level & $-0.05^{* * *}(-0.07,-0.03)$ & $1.68^{* * * *}(1.02,2.35)$ & $0.05^{* *}(0.01-0.09)$ & $0.05(-0.04,0.14)$ & $1.55^{* * * *}(0.68,2.42)$ & $0.72 * *(0.13-, 1.31)$ \\
\hline \multicolumn{7}{|c|}{ Model 3 Adjusted for Lifestyle characteristics/Health Behaviours } \\
\hline \multicolumn{7}{|l|}{ Education } \\
\hline \multicolumn{7}{|c|}{ High level(ref) } \\
\hline Low level & $-0.04 * * *(-0.06,-0.01)$ & $1.20 * * *(1.27,2.54)$ & $0.01(-0.02,0.04)$ & $0.05(-0.03,0.14)$ & $1.66 * * *(1.03,2.74)$ & $0.97 * * *(0.40-1.55)$ \\
\hline \multicolumn{7}{|c|}{ Model 4 Overall adjustment } \\
\hline \multicolumn{7}{|c|}{ Education } \\
\hline \multicolumn{7}{|c|}{ High level (ref) } \\
\hline Low level & $-0.02 *(-0.05,0.01)$ & $0.70^{* * * *}(0.065,1.30)$ & $-0.01(-0.05,0.04)$ & $-0.04(-0.15,0.05)$ & $1.48 * * * *(0.48,2.47)$ & $0.68 * *(0.01,1.36)$ \\
\hline
\end{tabular}

Notes: Table 3 represents unstandardised coefficient which expresses the change in outcome due to change from low to high CMLE adjusted for characteristics at birth, lifestyle characteristics and health behaviours. Model 2 was adjusted for "gender", 'mothers age at birth', "birthweight", "breastfeeding”; and' father's social class'. Model 3 was adjusted for gender', 'smoking at age 42', "alcohol frequency”, “exercise frequency”;' fruit', “sweet”,'BMl'. Model 4 was adjusted for education', “gender”,'mothers age at birth', “birthweight ",'breastfeeding';' father's social class', 'smoking at age 42', “alcohol frequency ",'exercise frequency'; fruit', "sweet”, 'BMl'. The, confidence interval is in parenthesis. $* * * \mathrm{p}<0.01, * * \mathrm{p}<0.05, * \mathrm{p}<0.1$.

involved separate adjustment for birth and lifestyle characteristics and health behaviours indicated a significant relationship between low CMLE and HDL-cholesterol. The significant relationship between CMLE and the blood lipid profile in terms of HDL-cholesterol and triglycerides was attenuated after overall adjustment for a combination of birth and lifestyle characteristics and health behaviours. Although CMLE may have a direct influence on the blood lipid level, other birth characteristics and lifestyle factors may exact more effect on the lipid level. Also, triglyceride concentration in the blood may be less stable due to the effects of recent meals. This is the reason why researchers normally require 12 hours of fasting before taking blood samples. ${ }^{23}$

The findings in this study were consistent with past studies that aimed to establish the association between individual educational level or maternal education and lipid profiles, especially HDL cholesterol and triglycerides. ${ }^{23-27}$ Some studies reported findings similar to this study, while the direction of the association between education and lipid profiles in some studies was opposite to in this study ${ }^{28-30}$ A possible explanation for the association between lower education level and lipid profile may be that participants whose parents are well educated are more likely to consume fruit, vegetables and food with less saturated fat. ${ }^{31,32}$ Selecting a diet with low saturated fat for a child was found to lead to an improved plasma lipid profile and will help to reduce atherosclerotic vascular disease over a life course. ${ }^{33}$ This was evidenced in some animal studies that showed that atherosclerosis was highly likely to develop in species of animal that are fed with diets that increase total and low-density lipoprotein level in the blood. ${ }^{34-37}$ Furthermore, in adults and children across many countries, the differences in lipid profile are determined by the amount or proportion of saturated fat in the diet. $^{38,39}$

\section{CMLE and HbAlc}

The result of the regression analysis showed that CMLE was associated with the risk of type 2 diabetes in midlife. The association became attenuated when adjusted for lifestyle characteristics and health behaviours in midlife. These findings were consistent with the results of past studies that indicated that children born to less educated parents are in a disadvantaged position which increases the risk of diabetes in midlife, ${ }^{40-45}$ although some of these 
findings were weak when study sample size, participants' gender and methodological designs were considered. In terms of gender, some past studies on the association between indicators of childhood SES and diabetes reported either weak or no association between maternal education and diabetes in men. ${ }^{40,43,45}$ Similarly, in other studies, the association between incidence of diabetes and childhood socioeconomic position was weak in women and there was no association in men. ${ }^{41,44}$

\section{CMLE and WC}

A significant result was recorded for the association between CMLE and WC. The unadjusted estimates indicated a significant association between CMLE and WC. After adjustment for birth and lifestyle/health behaviours the relationship stayed the same. Participants that had low CMLE were found to be more obese than those with high CMLE. The proportion of female participants with large WC was higher than the proportion of males. The findings in this study are in line with other studies that found that the educational level of parents has an impact on the weight of their offspring. ${ }^{46-48}$ Obesity is a key risk factor for many chronic health conditions. Unusual weight in adulthood could be a result of parental characteristics during childhood which, according to some studies, determine health outcomes in adulthood. ${ }^{47,49,50}$ Large WC, which signifies obesity, affects the body as a whole, including the cardiovascular and respiratory systems. ${ }^{51,52}$ It also impacts on the physiological, health and cognitive behaviours of an individual. Compared to paternal characteristics, maternal characteristics were found by many studies to have a stronger effect on the health behaviours and health status of children. ${ }^{49,53}$ CMLE is a strong determinant of children's health behaviours. Mothers with a lower level of education tend to feed their children more unhealthy food, which may negatively impact their health and wellbeing. ${ }^{49,50,54,55}$ The habits of unhealthy eating formed during childhood may be difficult to drop in adulthood. This could influence changes in body weight from childhood to adulthood.

The findings from this study should spur health professionals to design measures that will target different maternal levels of education. Strengthening the health education of mothers will help them to understand the benefits of proper nutrition and weight management in children. ${ }^{56}$

\section{CMLE and Blood Pressure}

Both crude and adjusted estimates indicated a significant association between CMLE and blood pressure in midlife.
The association between CMLE and blood pressure established in other studies has been confirmed in this study. ${ }^{57-}$ ${ }^{59}$ A possible explanation lies in the life course model, which suggests that early disadvantages in terms of SES could have effects on blood pressure through several mechanisms at each stage of life. ${ }^{60}$ In addition, it has been confirmed by some studies that the risk factors for atherosclerosis in adults are similar to those in childhood. ${ }^{61-63}$ Elevated blood pressure, which is one of the risk factors for atherosclerosis, is common in children in disadvantaged socioeconomic positions. Children born to mothers with lower levels of education are in a disadvantaged position ${ }^{64}$ due to the prevalence of some health behaviour risk factors, such as lack of physical exercise, high intake of dietary sodium and obesity, which have adverse effects on blood pressure. ${ }^{65-68}$ These health behaviours acquired during childhood often persist into adulthood. The effect of elevated blood pressure in childhood might lead to increased blood pressure in adulthood, as individuals with high blood pressure in childhood are more likely to have elevated blood pressure in adulthood, and vice versa. ${ }^{69}$ Therefore, the early stages of life seem to be critical for hypertension and cardiovascular abnormalities in adulthood. ${ }^{70,71}$

Prevention of hypertension in adulthood should start as early as possible and should aim at modification of lifestyle factors including increasing physical activity, reducing sodium in the diet, body weight management and frequent consumption of fruit, vegetables, fibre and low-fat dairy.

\section{Strengths and Limitations}

The survey sweeps and biomedical survey of the NCDS are prospective in nature. As a result, "recall bias" is not a major issue in this kind of study. A recall bias is said to occur when participants give inaccurate or questionable accounts of an event during an interview. ${ }^{72}$ The outcome measures such as HDL-cholesterol, triglyceride, $\mathrm{HbAlc}$, WC and blood pressure used in this study were obtained directly from participants by qualified professionals and did not require participants to recall any value which could lead to inaccurate results. In addition, the issue of measurement bias $^{73}$ was minimised because values recorded for measures such as WC and blood pressure were obtained from the average of 3 measurements taken at specified time intervals. Also, the outcome measures obtained from the blood sample, including HDLcholesterol, triglyceride, and $\mathrm{HbAlc}$ were obtained from laboratory analysis with no interference from participants 
or researchers. Over $90 \%$ of participants had English as their first language; therefore, instructional materials and guidelines relating to each survey sweep was assumed to be well understood. ${ }^{74}$ Multiple imputation was used to handle missing data. Under a missing at random (MAR) assumption, data were imputed for missing values in both independent and outcome variables. The results of both multiple imputation and complete case analysis were similar when compared. The multiple imputation results in increased sample size and less bias in the result. In terms of limitation, HbAlc was used as a risk marker of MetS instead of fasting glucose because it was easier to obtain from participants. $\mathrm{T}$ results may be different if $\mathrm{FG}$ was used.

\section{Data Sharing Statement}

The datasets analysed during the current study are available in the UK data service repository, https://www.ukda taservice.ac.uk/get-data. The NCDS biomedical survey data is made available by applying for a special license to UK Data Service.

\section{Ethics Approval}

This study was approved by the research ethics committee of the University of Bedfordshire (No. IHREC828) to carry out this research. A special license (No11906) for NCDS biomedical survey data was granted by the UK Data service.

\section{Acknowledgments}

The authors thank the UK Data Service and Centre for Longitudinal Studies for granting a special license to use NCDS biomedical data. The authors are also grateful to the Research Ethics Committee of the University of Bedfordshire for approval to carry out this study.

\section{Author Contributions}

All authors made substantial contributions to conception and design, acquisition of data, or analysis and interpretation of data; took part in drafting the article or revising it critically for important intellectual content; agreed to submit to the current journal; gave final approval of the version to be published; and agree to be accountable for all aspects of the work.

\section{Funding}

There is no funding to report.

\section{Disclosure}

The authors declare that they have no competing interests.

\section{References}

1. Kaur J. A comprehensive review on metabolic syndrome. Cardiol Res Pract. 2014;2014:1-21. doi:10.1155/2014/943162.

2. Eckel RH, Grundy SM, Zimmet PZ. The metabolic syndrome. Lancet. 2005. doi:10.1016/S0140-6736(05)66378-7.

3. NCEP (2001) Third Report of the National Cholesterol Education Program (NCEP) Expert Panel on, 01-3670. doi:10.1001/ jama.285.19.2486.

4. Wang Y, Lim H, Wu Y. Growing global burden of chronic noncommunicable diseases and an alarming situation in China. Beijing Da Xue Xue Bao Yi Xue Ban = Journal of Peking University Health Sciences. 2012.

5. Ogunsina K, Dibaba DT, Akinyemiju T. Association between life-course socio-economic status and prevalence of cardio-metabolic risk factors in five middle-income countries. J Glob Health. 2018;8(2). doi:10.7189/jogh.08.020405.

6. Carnethon MR, Loria CM, Hill JO, et al. Risk factors for the metabolic syndrome. Diabetes Care. 2004. doi:10.2337/DIACARE.27.11.2707.

7. Fan AZ, Russell M, Naimi T, et al. Patterns of alcohol consumption and the metabolic syndrome. $J$ Clin Endocrinol Metabol. 2008;93 (10):3833-3838. doi:10.1210/jc.2007-2788.

8. Fujita N, Takei Y. Alcohol consumption and metabolic syndrome. Hepatol Res. 2011;41(4):287-295. doi:10.1111/j.1872-034X.2011.00787.x.

9. Golbidi S, Mesdaghinia A, Laher I. Exercise in the metabolic syndrome. Oxid Med Cell Longev. 2012;2012:1-13. doi:10.1155/ 2012/349710.

10. Sun K, Liu J, Ning G. Active smoking and risk of metabolic syndrome: a meta-analysis of prospective studies. PLoS One. 2012. doi:10.1371/journal.pone.0047791.

11. Ministry of Education. 1998. Education Act $1996^{\prime}$, in (Act 550) Part IV, National Education System.

12. Cowan S, McCulloch G, Woodin T. From HORSA huts to ROSLA blocks: the school leaving age and the school building programme in England, 1943-1972'. Hist Educ. 2012;41(3):361-380. doi:10.1080/ 0046760X.2011.585143.

13. Andrews L. The education act, 1918. 2016. doi:10.4324/9781315446561.

14. Batteson CH. The 1944 education act reconsidered'. Educ Rev. 1999;51(1):5-15. doi:10.1080/00131919997632.

15. Parliament UK. The Education Act of 1944, About Parliament: living Heritage. 2010.

16. Keen H. The Diabetes Control and Complications Trial (DCCT). Health Trends. 1994. doi:10.5694/j.1326-5377.1993.tb141357.x.

17. He Y, Qiao Q, Tuomilehto J, et al. Prevalence of the metabolic syndrome and its relation to cardiovascular disease in an elderly Chinese. J Am Coll Cardiol. 2006. doi:10.1016/j.jacc.2005.11.074.

18. Montez JK, Bromberger JT, Harlow SD, et al. Life-course socioeconomic status and metabolic syndrome among midlife women. $J$ Gerontol Ser B Psychol Sci Soc Sci. 2016;71(6):1097-1107. doi:10.1093/geronb/gbw014.

19. Velazquez-Bautista M, López-Sandoval JJ, González-Hita M, et al. Association of metabolic syndrome with low birth weight, intake of high-calorie diets and acanthosis nigricans in children and adolescents with overweight and obesity. Endocrinol Diabetes Nutri. 2017. doi:10.1016/j.endinu.2016.09.004.

20. Villareal DT, Miller BV, Banks M, et al. Effect of lifestyle intervention on metabolic coronary heart disease risk factors in obese older adults. Am J Clin Nutri. 2006;84(6):1317-1323. doi:10.1093/ajcn/ 84.6.1317.

21. Wannamethee SG, Shaper AG, Whincup PH. Modifiable lifestyle factors and the metabolic syndrome in older men: effects of lifestyle changes. J Am Geriatr Soc. 2006;54(12):1909-1914. doi:10.1111/ j.1532-5415.2006.00974.x. 
22. Wisnieski L, Kerver J, Holzman C, et al. Breastfeeding and risk of metabolic syndrome in children and adolescents: a systematic review. J Human Lactation. 2018;34(3):515-525. doi:10.1177/089033441773 7038.

23. Lara M, Amigo H. Association between education and blood lipid levels as income increases over a decade: a cohort study. BMC Public Health. 2018;18(1). doi:10.1186/s12889-018-5185-3.

24. Benetou V, Chloptsios Y, Zavitsanos X, et al. Total cholesterol and HDL-cholesterol in relation to socioeconomic status in a sample of 11,645 Greek adults: the EPIC study in Greece. European Prospective Investigation into Nutrition and Cancer. Scand J Public Health. 2000;28(4):260-265. doi:10.1177/14034948000280040801

25. Iribarren C, Twelve-year trends in cardiovascular disease risk factors in the Minnesota heart survey: are socioeconomic differences widening?. Arch Intern Med. 1997;157(8):873. doi:10.1001/archinte.157.8.873.

26. Quispe R, Benziger CP, Bazo-Alvarez JC, et al. The relationship between socioeconomic status and CV risk factors: the CRONICAS cohort study of Peruvian adults. Glob Heart. 2016;11(1):121. doi:10.1016/j.gheart.2015.12.005.

27. Shohaimi S, Boekholdt MS, Luben R, et al. Distribution of lipid parameters according to different socio-economic indicators - the EPIC-Norfolk prospective population study. BMC Public Health. 2014;14(1). doi:10.1186/1471-2458-14-782.

28. Davey Smith G, Hart C, Watt G, Hole D, Hawthorne V. Individual social class, area-based deprivation, cardiovascular disease risk factors, and mortality: the Renfrew and Paisley study. J Epidemiol Community Health. 1998. doi:10.1136/jech.52.6.399.

29. Espírito LR, et al. Socioeconomic status and education level are associated with dyslipidemia in adults not taking lipid-lowering medication: a population-based study. Int Health. 2019: 1-8. doi:10.1093/ inthealth/ihz089.

30. Garrison RJ, Gold RS, Wilson PWF, et al. Educational attainment and coronary heart disease risk: the Framingham offspring study. Prev Med. 1993;22(1):54-64. doi:10.1006/pmed.1993.1004.

31. Darmon N, Drewnowski A. Does social class predict diet quality?. Am J Clin Nutri. 2008;87(5):1107-1117. doi:10.1093/ajcn/87.5.1107.

32. Pechey R, Monsivais P. Socioeconomic inequalities in the healthiness of food choices: exploring the contributions of food expenditures. Prev Med. 2016;88:203-209. doi:10.1016/j.ypmed.2016.04.012.

33. McGill J, et al. Origin of atherosclerosis in childhood and adolescence. Am J Clin Nutri. 2000. doi:10.1093/ajcn/72.5.1307s.

34. Getz GS, Reardon CA. Animal models of atherosclerosis. Animal Models Study Human Dis. 2017. doi:10.1016/B978-0-12-8094686.00008-5.

35. Jawień J, Nastałek P, Korbut R. 'Mouse models of experimental atherosclerosis'. J Physiol Pharmacol. 2004.

36. Lee YT, et al. Mouse models of atherosclerosis: a historical perspective and recent advances'. Lipids Health Dis. 2017. doi:10.1186/ s12944-016-0402-5.

37. Leong X-F, Ng C-Y, Jaarin K. Animal models in cardiovascular research: hypertension and atherosclerosis. Biomed Res Int. 2015;2015:1-11. doi:10.1155/2015/528757.

38. Grande F, Anderson JT, Keys A. Diets of different fatty acid composition producing identical serum cholesterol levels in man. Am J Clin Nutri. 1972;25(1):53-60. doi:10.1093/ajen/25.1.53.

39. Klish WJ, et al. Cholesterol in childhood. Pediatrics. 1998. doi:10.1542/peds.101.1.141.

40. Best LE, Hayward MD, Hidajat MM. Life course pathways to adult-onset diabetes. Soc Biol. 2005;52(3-4):94-111. doi:10.1080/ 19485565.2005.9989104.

41. Demakakos P, Marmot M, Steptoe A. Socioeconomic position and the incidence of type 2 diabetes: the ELSA study. Eur J Epidemiol. 2012;27(5):367-378. doi:10.1007/s10654-012-9688-4.

42. Lidfeldt J, Li TY, Hu FB, et al. 'A prospective study of childhood and adult socioeconomic status and incidence of type 2 diabetes in women'. Am J Epidemiol. 2007;165(8):882-889. doi:10.1093/aje/kwk078.
43. Maty SC, Lynch JW, Raghunathan TE, et al. Childhood socioeconomic position, gender, adult body mass index, and incidence of type 2 diabetes mellitus over 34 years in the Alameda county study. Am J Public Health. 2008;98(8):1486-1494. doi:10.2105/AJPH.2007.123653.

44. Robbins JM, Vaccarino V, Zhang H, Kasl SV. Socioeconomic status and type 2 diabetes in African American and non-Hispanic White women and men: evidence from the Third National Health and Nutrition Examination Survey. Am J Public Health. 2001. doi:10.2105/AJPH.91.1.76.

45. Smith BT, Lynch JW, Fox CS, et al. Life-course socioeconomic position and type 2 diabetes mellitus the Framingham offspring study. Am J Epidemiol. 2011;173(4):438-447. doi:10.1093/aje/kwq 379.

46. Ball K, Mishra GD. Whose socioeconomic status influences a woman's obesity risk: her mother's, her father's, or her own? Int $J$ Epidemiol. 2006;35(1):131-138. doi:10.1007/s10623-0055666-0.

47. Naess M, Sund ER, Holmen TL, Kvaløy K. Implications of parental lifestyle changes and education level on adolescent offspring weight: a population based cohort study - The HUNT Study, Norway. BMJ Open. 2018. doi:10.1136/bmjopen-2018-023406.

48. Semmler C, Ashcroft J, van Jaarsveld CHM, et al. 'Development of overweight in children in relation to parental weight and socioeconomic status. Obesity. 2009;17(4):814-820. doi:10.1038/oby.2008. 621.

49. van Ansem WJC, Schrijvers CT, Rodenburg G, et al. Maternal educational level and children's healthy eating behaviour: role of the home food environment (cross-sectional results from the INPACT study). Int $J$ Behav Nutri Phys Activity. 2014;11(1). doi:10.1186/s12966-014-0113-0.

50. Saldiva SRDM, Venancio SI, de Santana AC, et al. The consumption of unhealthy foods by Brazilian children is influenced by their mother's educational level. Nutr J. 2014;13(1). doi:10.1186/14752891-13-33.

51. Guagnano MT, Ballone E, Colagrande V, et al. 'Large waist circumference and risk of hypertension'. Int J Obes. 2001;25(9):1360-1364. doi:10.1038/sj.ijo.0801722.

52. Janssen I, Katzmarzyk PT, Ross R. Waist circumference and not body mass index explains obesity-related health risk. Am J Clin Nutri. 2004;79(3):379-384. doi:10.1093/ajen/79.3.379.

53. Keane E, Layte R, Harrington J, et al. 'Measured parental weight status and familial socio-economic status correlates with childhood overweight and obesity at age 9'. PLoS One. 2012;7(8):e43503. doi: 10.1371 /journal.pone. 0043503 .

54. Bogea EG, et al. Eating patterns among children aged 13 to 35 months nd association with maternal characteristics. Cad Saude Publica. 2019. doi:10.1590/0102-311x00072618.

55. Okubo H, Miyake Y, Sasaki S, et al. Dietary patterns in infancy and their associations with maternal socio-economic and lifestyle factors among 758 Japanese mother-child pairs: the Osaka Maternal and Child Health Study. Matern Child Nutr. 2014;10(2):213-225. doi:10.1111/j.1740-8709.2012.00403.x.

56. Feng F, Ding L, Tang X, Wang Y, Zhou C. Association between maternal education and school-age children weight status: a study from the China health nutrition survey, 2011. Int J Environ Res Public Health. 2019;16(14):2543. doi:10.3390/ijerph16142543.

57. Bouthoorn SH, et al. 'Maternal educational level and blood pressure, aortic stiffness, cardiovascular structure and functioning in childhood: the generation R study'. Am J Hypertens. 2014. doi:10.1093/ajh/hpt180.

58. Kwok MK, Mary SC, Leung GM, Subramanian SV. Grandparental education, parental education and adolescent blood pressure. Prev Med. 2016. doi:10.1016/j.ypmed.2016.06.015.

59. Kwok MK, Schooling CM, Subramanian SV, et al. 'Pathways from parental educational attainment to adolescent blood pressure'. J Hypertens. 2016;34(9):1787-1795. doi:10.1097/HJH.0000000000 001003. 
60. Yu S. The life-course approach to health'. Am J Public Health. 2006;96(5):768. doi:10.2105/AJPH.2006.088617.

61. Couch SC, Daniels SR. Diet and blood pressure in children. Curr Opin Pediatr. 2005;17(5):642-647. doi:10.1097/01.mop.00001728 17.87261.4f.

62. Lazarou C, Panagiotakos DB, Matalas AL. Lifestyle factors are determinants of children's blood pressure levels: the CYKIDS study. J Hum Hypertens. 2009;23(7):456-463. doi:10.1038/jhh.20 08.151 .

63. Williams CL, Hayman LL, Daniels SR, et al. Cardiovascular health in childhood: a statement for health professionals from the Committee on Atherosclerosis, Hypertension, and Obesity in the Young (AHOY) of the Council on Cardiovascular Disease in the Young, American Heart Association'. Circulation. 2002;106(1):143-160. doi:10.1161/01.CIR. 0000019555.61092.9E.

64. Power C, Matthews S. Origins of health inequalities in a national population sample. Lancet. 1997;350(9091):1584-1589. doi:10.1016/ S0140-6736(97)07474-6.

65. Arroll B, Beaglehole R. 'Does physical activity lower blood pressure: a critical review of the clinical trials'. J Clin Epidemiol. 1992;45 (5):439-447. doi:10.1016/0895-4356(92)90093-3.

66. De Gaudemaris R, Lang T, Chatellier G, et al. Socioeconomic inequalities in hypertension prevalence and care: the IHPAF study. Hypertension. 2002;39(6):1119-1125. doi:10.1161/01.HYP.00000189 12.05345 .55
67. Stamler R, Shipley M, Elliott P, et al. Higher blood pressure in adults with less education: some explanations from INTERSALT. Hypertension. 1992;19(3):237-241. doi:10.1161/01.HYP.19.3.237.

68. Yang Q, Zhang Z, Kuklina EV, et al. Sodium intake and blood pressure among US children and adolescents. Pediatrics. 2012;130 (4):611-619. doi:10.1542/peds.2011-3870.

69. Kivimäki M, Lawlor DA, Smith GD, et al. Early socioeconomic position and blood pressure in childhood and adulthood: the cardiovascular risk in young finns study'. Hypertension. 2006;47(1):39-44. doi:10.1161/01.HYP.0000196682.43723.8a.

70. Chen X, Wang Y. Tracking of blood pressure from childhood to adulthood: a systematic review and meta-regression analysis. Circulation. 2008;117 (25):3171-3180. doi:10.1161/CIRCULATIONAHA.107.730366.

71. Eriksson JG, Forsén TJ, Kajantie E, et al. Childhood growth and hypertension in later life. Hypertension. 2007;49(6):1415-1421. doi:10.1161/HYPERTENSIONAHA.106.085597.

72. Raphael K. Recall bias: a proposal for assessment and control. Int J Epidemiol. 1987;16(2):167-170. doi:10.1093/ije/16.2.167.

73. Olson K. Survey participation, nonresponse bias, measurement error bias, and total bias. Public Opin Q. 2006;70(5):737-758. doi: $10.1093 /$ poq $/$ nfl038.

74. Egger M, Zellweger-Zähner T, Schneider M, et al. Language bias in randomised controlled trials published in English and German. Lancet. 1997;350(9074):326-329. doi:10.1016/S0140-6736(97)024 19-7.

Diabetes, Metabolic Syndrome and Obesity: Targets and Therapy

Dovepress

\section{Publish your work in this journal}

Diabetes, Metabolic Syndrome and Obesity: Targets and Therapy is an international, peer-reviewed open-access journal committed to the rapid publication of the latest laboratory and clinical findings in the fields of diabetes, metabolic syndrome and obesity research. Original research, review, case reports, hypothesis formation, expert opinion and commentaries are all considered for publication. The manuscript management system is completely online and includes a very quick and fair peer-review system, which is all easy to use. Visit $\mathrm{http}: / / \mathrm{www}$.dovepress.com/testimonials.php to read real quotes from published authors. 